\title{
Hybrid Organic-Inorganic Assemblies Based on Molybdates and Dimethyltin Linkers
}

\author{
Santiago Reinoso, Michael H. Dickman, Markus Reicke and Ulrich Kortz* \\ School of Engineering and Science, International University Bremen, P. O. Box 750 561, 28725 \\ Bremen, Germany
}

Supporting Information

Figure S1. Infrared spectra of compounds 1-3

Figure S2. Thermograms of compounds 1 and $\mathbf{2}$

Figure S2. Thermograms of compound 3 


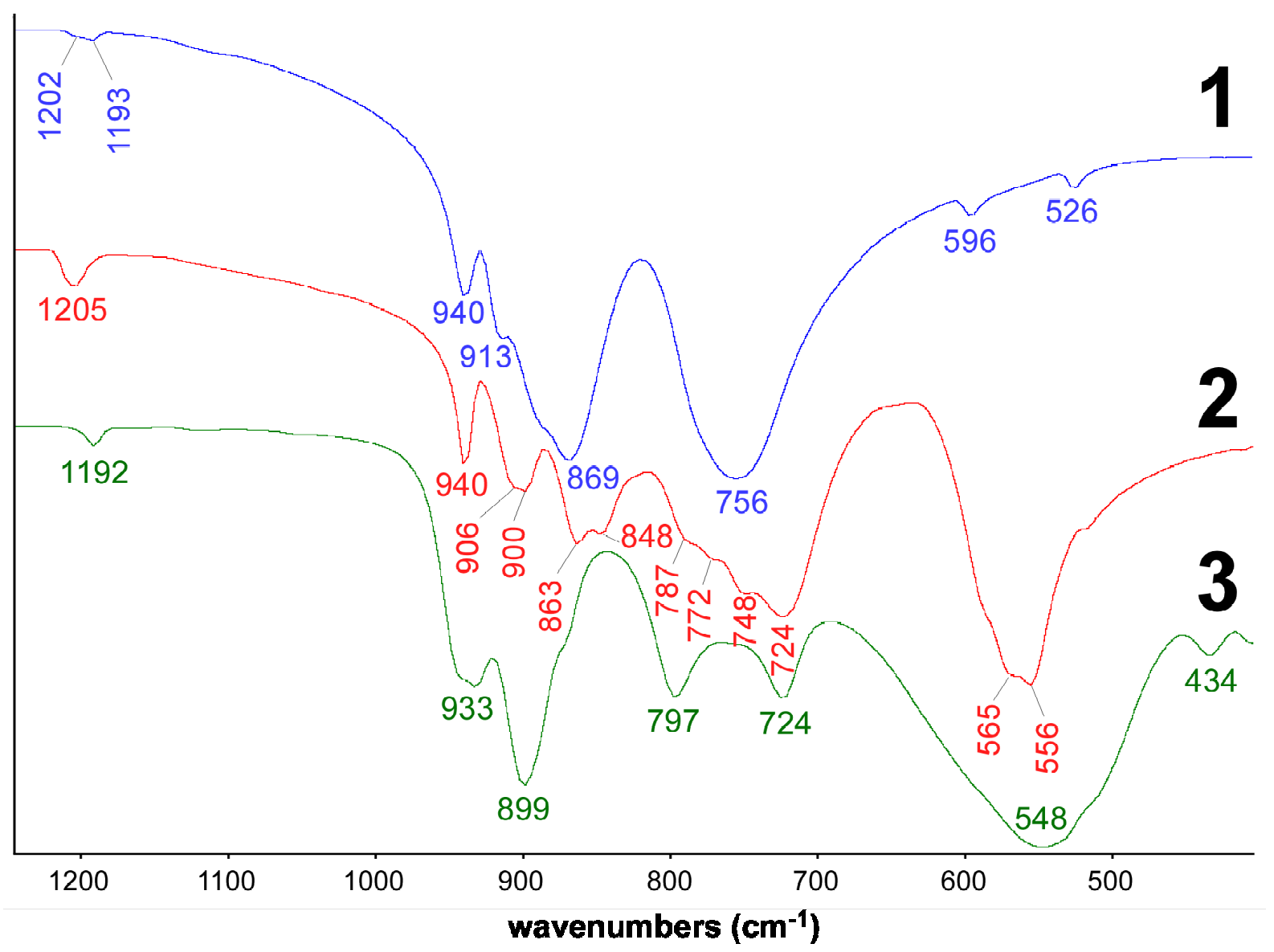

Figure S1 


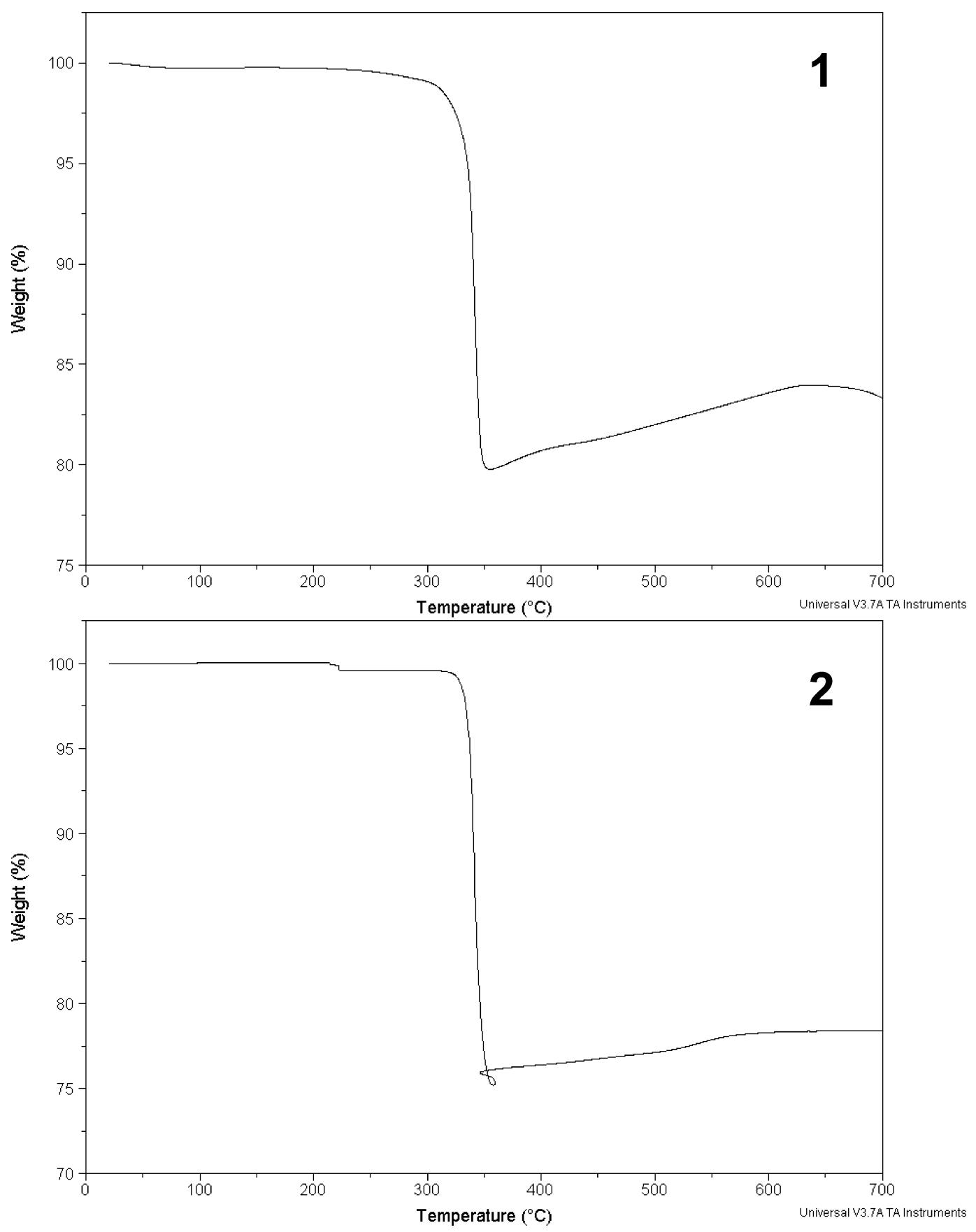

Figure S2 


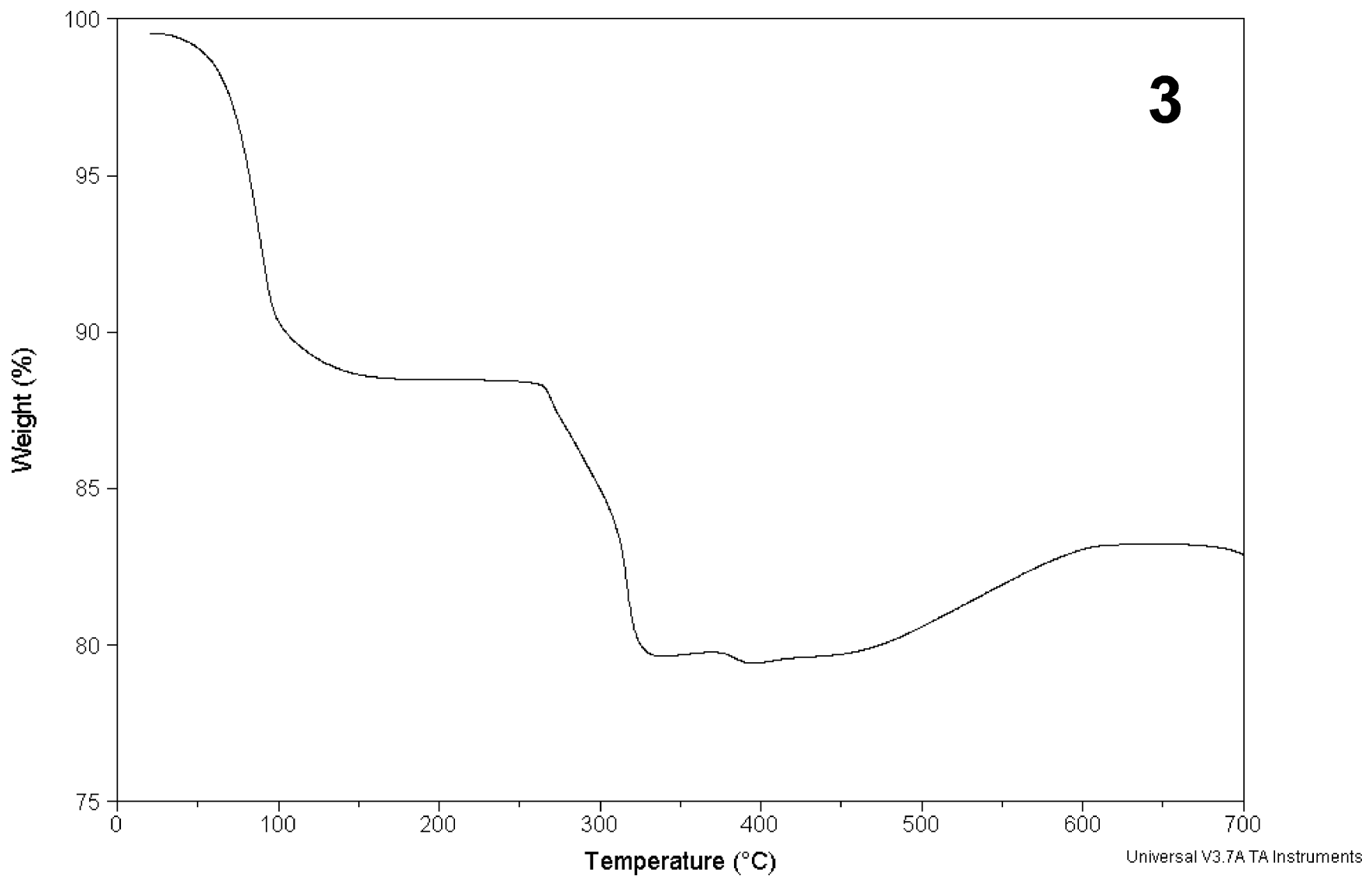

Figure S3 